\title{
Fibreglass dermatitis in a caravan manufacturer manifesting as prurigo nodularis
}

Erick Bravo, Claire M. Felmingham and Rosemary L. Nixon

Occupational Dermatology Research and Education Centre, Skin and Cancer Foundation Inc, Carlton, Melbourne, Australia.

Correspondence:

Dr. Claire M. Felmingham, Occupational Dermatology Research and Education Centre, Skin and Cancer Foundation Inc, Level 1/80 Drummond St, Carlton, Melbourne, Victoria 3053, Australia. e-mail: clairefelmingham@gmail.com

Conflict of interests: None to declare

Key words: case report, fibreglass, fibreglass dermatitis, nodular, prurigo nodularis, patch test, irritant contact dermatitis, caravan

Exposure to fibreglass is a well-known cause of irritant contact dermatitis, and fibreglass particles may cause pruritus. A variety of possible skin lesions arising from the mechanical irritation of fibreglass particles have been reported. We describe a case of fibreglass contact dermatitis presenting with prurigo nodularis-like lesions.

\section{Case Report}

A 62-year-old man employed as a glass cutter in a caravan manufacturing facility was referred to our occupational dermatology clinic complaining of an itchy rash, which started one year prior (Figures 1A and 1B). He had worked in this job for one year and developed the rash soon after starting this role. He cut fibreglass with a rotating cutting tool while wearing long sleeves, plastic overalls and a variety of gloves. In addition to handling the fibreglass, he was exposed to fibreglass dust generated by a co-worker cutting fibreglass nearby. There was a small area of exposed skin at his wrists, between his gloves and overalls. The rash started on his ventral wrists, but then extended to his arms, abdomen, and legs. He had no prior history of atopy nor other skin conditions.

This is the author manuscript accepted for publication and has undergone full peer review but has not been through the copyediting, typesetting, pagination and proofreading process, which may lead to differences between this version and the Version of Record. Please cite this article as doi: $10.1111 / \operatorname{cod} .13333$

This article is protected by copyright. All rights reserved. 
After consulting several doctors, he was treated for prurigo nodularis, using topical corticosteroids, oral antihistamines, oral antibiotics, and phototherapy. His pruritic nodules continued despite treatment, but notably, his skin improved significantly when he had a one-month holiday from work. Once the work-relatedness was recognised, the worker filed a successful workers' compensation claim and experienced gradual improvement of his skin condition when away from the workplace.

The patient was patch-tested to the Australian baseline series, rubber chemicals, epoxy chemicals, formaldehyde resins, and samples of his own products from home and work. Testing was performed using allergEAZE skin patch test chambers and allergens were obtained from allergEAZE (Smart Practice, Phoenix, Arizona) and Chemotechnique Diagnostics (Vellinge, Sweden) and applied for 2 days. Patch test readings were made on day (D) 2 and D4 according to ICDRG guidelines. All patch tests were negative. Screening blood tests for causes of pruritus were normal or negative. A skin biopsy taken by a previous doctor had been initially reported to be consistent with prurigo or lichen simplex. We requested review with examination under polarized light, which revealed small particles of birefringent material in the stratum corneum, confirming the diagnosis of fibreglass dermatitis (Figure 2).

\section{Discussion}

Fibreglass was first described in 1942 to cause irritant contact dermatitis (1). Sharp, fine fragments of fibreglass penetrate the stratum corneum and cause mechanical irritation. While it has been more often reported in adults, it has also been described in children (2). Fibreglass dermatitis has predominantly been described in occupational settings. The material is used extensively in caravan manufacture. Caravan sales are booming in Australia and a 2018 consumer report found that 1 in 13 Australian households have a registered recreational vehicle (3).

Fibreglass dermatitis may present with a variety of skin lesions, or no skin lesions. Reported clinical presentations include papules, vesicles, excoriations, erythema, lichenification, and desquamation, typically involving the hands, face, forearms and skin folds (4). Rare cases have been described as purpuric, urticarial, granuloma anulare or erythema multiforme-like (5). Sometimes fibreglass has been spread through laundering fibreglass-contaminated clothes (6).

This article is protected by copyright. All rights reserved. 
Surprisingly, a prurigo nodularis-like presentation of fibreglass dermatitis has not been reported, to our knowledge. Prurigo nodularis-like presentations have been reported in the context of other types of irritant contact dermatitis, such as diaper dermatitis (7) and in cases of allergic contact dermatitis to gold, chloramphenicol, and $p$-phenylenediamine (810) (11).

Prurigo nodularis is a variant of chronic prurigo. It begins with a trigger that may be systemic, neurological, psychosomatic or unknown, which leads to pruritus, increased scratching of skin and the eventual formation of pruriginous lesions (11). In this case, the exposure to fibreglass caused intense pruritus, and subsequent activation of the itch-scratch cycle formed non-eczematous nodular lesions. Prurigo nodularis may coexist with conditions like atopic dermatitis but is recognised as a separate entity (12).

Fibreglass dermatitis diagnosis can be confirmed with visualisation of fibreglass particles in the skin, via skin biopsy and histological examination under polarised light (such as in our case); adhesive tape tests from affected skin; or the more recent in vivo reflectance confocal microscopy (13). In conclusion, fibreglass dermatitis should be suspected in all cases where there is potential fibreglass exposure, even when the clinical presentation is atypical.

\section{References}

1. Sulzberger M, Baer R. The effects of fiber glass on animal and human skin. Ind Med Surg. 1942;11:482-4.

2. Cusano F, Mariano M. Fiberglass dermatitis microepidemic in a primary school. Contact Dermatitis. 2007;57:351-2.

3. RV Consumer 2018. Brisbane, Australia: Caravan Industry Association of Australia; 2019.

4. Camacho I, Rajabi-Estarabadi A, et al. Fiberglass dermatitis: clinical presentations, prevention, and treatment - a review of literatures. Int J Dermatol. 2019.

5. Sertoli A, Francalanci S, Giorgini S. Fiberglass dermatitis. In: Kanerva L, Wahlberg JE, Elsner P, Maibach HI, editors. Handbook of Occupational Dermatology. 1st ed. Berlin: Springer; 2000. p. 122-34.

6. Lucas JB. Common industrial dermatoses. Cutis. 1974;33(13).

7. Maruani A, Lorette G, Barbarot S, et al. Re-emergence of papulonodular napkin dermatitis with use of reusable diapers: report of 5 cases. Eur J Dermatol. 2013;23:246-9. 
8. Romita P, Stingeni L, Hansel K, et al. Allergic contact dermatitis caused by chloramphenicol with prurigo nodularis-like spreading. Contact Dermatitis. 2019;80:251-2. 9. Mehta V, Balachandran C. Persistent nodular contact dermatitis to gold: case report of two cases. Indian J Dermatol Venereol Leprol. 2010;76:397-9.

10. Verma P, Yadav P. Paraphenylenediamine dye allergic contact dermatitis of mustache region manifesting as prurigo nodularis-like lesions. Dermatitis. 2014;25:91-2.

11. Pereira MP, Steinke S, Zeidler C, et al. European academy of dermatology and venereology European prurigo project: expert consensus on the definition, classification and terminology of chronic prurigo. J Eur Acad Dermatol Venereol. 2018;32:1059-65.

12. Zeidler C, Yosipovitch G, Stander S. Prurigo Nodularis and Its Management. Dermatol Clin. 2018;36:189-97.

13. Eber AE, Sanchez M, Lee N, Perper M, Cervantes J, Tosti A. Confocal microscopy in the diagnosis of fibreglass dermatitis. Contact Dermatitis. 2017;77:266-7.

Figure legend

Figure $1 \mathrm{~A}$ and $1 \mathrm{~B}$ - Prurigo nodularis-like eruption

Figure 2 - Histopathology: small particles of birefrigent material seen in the stratum corneum with polarised light microscopy

This article is protected by copyright. All rights reserved. 


\section{University Library}

\section{- M M N E R VA A gateway to Melbourne's research publications}

Minerva Access is the Institutional Repository of The University of Melbourne

Author/s:

Bravo, E;Felmingham, CM;Nixon, RL

Title:

Fibreglass dermatitis in a caravan manufacturer manifesting as prurigo nodularis

Date:

2019-11-01

Citation:

Bravo, E., Felmingham, C. M. \& Nixon, R. L. (2019). Fibreglass dermatitis in a caravan manufacturer manifesting as prurigo nodularis. CONTACT DERMATITIS, 81 (5), pp.381-383. https://doi.org/10.1111/cod.13333.

Persistent Link:

http://hdl.handle.net/11343/286127 